\title{
Scoring Method of Assessment: Relevance and Perspective
}

\author{
Andrey Gusev ${ }^{1, *}$, Alina Invdeeva $^{2}$, and Polina Motuzenko ${ }^{2}$ \\ ${ }^{1}$ Financial University under the Government of the Russian Federation, Moscow, Russia \\ ${ }^{2}$ Institute of Distance and Open Education, Financial University under the Government of the Russian \\ Federation, Moscow, Russia
}

\begin{abstract}
The article reveals the essence of banking scoring and the importance of compiling high-quality scoring models for assessing risks when working with borrowers. The complexity of processing surface information about the borrower and the need for clarification with additional questions are indicated. The history and causes of the appearance of scoring modeling in the middle of the 20th century are described. The main criteria for scoring used to create algorithms for assessing the financial reliability of the borrower are listed. The contribution of post-Soviet scientists to the improvement of scoring models is indicated. Further prospects of banking scoring and its relevance in the light of the emergence of more progressive evaluation programs.
\end{abstract}

Keywords: underwriter, scoring, scoring models, application-scoring.

\section{Introduction}

The creditworthiness of the borrower is one of the most significant factors that creditors need to be aware of in the context of building and improving market relations. Financial institutions create and develop their own algorithms in order to determine the creditworthiness of business entities. However, for this purpose it is necessary to establish precisely what aspects the concept of creditworthiness incorporates in a market economy. It will be useful to pay attention to the fact that in the circumstances of the planned economy, when there was a distortion of lending principles and there was an acute lack of a foundation for the effective creation of credit relations, the idea of creditworthiness as an ability of an economic entity to fulfill its obligations was absent.

Since the planning policy framework of financial resources separation did not involve the use of free market relations, as a result there was no need for an analysis of the economic entity creditworthiness. However, during the transition to market relations, the order of economic relations between borrowers and creditors has significantly changed for the better.

In the new economy, the main role was played by the possibilities of such interaction, in which both the creditor and the borrower would benefit. It should also be noted that at the beginning of the market relations development the general interest in the deal between the borrower and the creditor was directly related to the assessment of creditworthiness. During that time opportunities and tools to assess this aspect of the financial and economic activity of the

*Corresponding author: gusevaa@yandex.ru 
economic actor appeared. In this context, different definitions of "creditworthiness" should be considered in order to eventually identify the definition that best reflects the creditworthiness of the borrower.

\section{Literary research}

Creditworthiness means the ability of an enterprise to meet its credit obligations, while solvency means the ability to meet all obligations, not only credit. It should also be noted that creditworthiness is a forecast of the ability to fulfill obligations to creditors at the current moment, while solvency is a direct opportunity to fulfill credit obligations at the current moment. Therefore, solvency is an opportunity to fulfill credit obligations, and creditworthiness is a forecast of such an opportunity.

One approach to defining creditworthiness assumes that it is a set of different conditions that determine the capacity of the borrower to raise borrowed resources and return them in full and on time - the definition of M.N. Kreinina [1]. In this approach, creditworthiness is considered in a broader sense. In particular, due attention is paid to the prerequisites for obtaining borrowed capital, such as the structure of the working capital used, the financial stability of the enterprise, the valuation of products within the framework of the demand for these products, and the liquidity of the assets of the borrower enterprise.

Thus, when determining creditworthiness, it is necessary to take into account all aspects coming from the three basic principles of the credit - payment, return and urgency. That is, you need to pay attention not only to the fact that the borrowed funds need to be returned within the period established by the loan agreement, but also to the fact that in addition to the principal debt, interest on the loan must be paid [2]. Moreover, it is necessary to take into account all the most important aspects in determining the probability of the borrower to fulfil his credit obligations, notably the factors of business risk, financial risk and credit history risk.

Based on all of the above, it is possible to define the creditworthiness of a borrower enterprise as its complex financial and legal characteristic, represented both by financial risk indicators and business risk indicators. Creditworthiness in this sense shows the capacity of an enterprise to fully meet its credit obligations in the future in accordance with a loan agreement and determines the degree of risk a bank bears while lending to a particular borrower.

It is particularly difficult to directly obtain fair, verified and objective results of assessing the creditworthiness of the business subject. This problem is solved by implementing systematic and comprehensive methods for analyzing a specific enterprise or in other words the borrower. The use of integrated economic analysis takes into account the most important aspects of the business entity's activities, such as a study of all aspects of the enterprise's activities and a detailed assessment of the relations between the sections of the analysis. Also, in the process of integrated economic analysis, indicators and factors of production are studied.

As part of the integrated economic analysis, creditworthiness is determined by the results of the economic activity of the company and indicates how effectively the management of it allocates financial resources, efficiently uses its own funds, proportionally combines equity and borrowed capital. Also, in this context, creditworthiness shows what are the results of the company's economic activities and what are the relations with counterparties represented by suppliers, buyers, other creditors, the state and others. As a result, the creditworthiness of the economic entity shows the competitiveness of the enterprise, its economic potential. At the same time, for a creditor of an enterprise, information about the creditworthiness of a particular enterprise can reduce the risks of loss due to the likelihood of financial difficulties resulting in the eventual impairment of a loan.

Consequently, information about the financial condition of the company is a serious advantage of the borrower to receive borrowed capital, as it shows the structure of equity and borrowed capital. Also, which is important, according to the structure of the capital, it is 
possible to assess how capital is distributed among various types of property and how efficiently capital is used. This is followed by an analysis of solvency, financial sustainability, an analysis of the economic potential of the borrower and its attractiveness to creditors. In the context of the borrower's financial status analysis, between financial analysis and creditworthiness arises an interconnection [20].

It should be noted that the fundamental principle of borrower's creditworthiness analysis is the systematic approach as part of a comprehensive economic analysis. This principle means that creditworthiness analysis is an element of a high-level system, to be more precise of integrated economic analysis system, and it has relationships with other subsystems. Also, creditworthiness analysis is an element of a lower level subsystem, that includes some subsystems or in other words stages of analysis. Figure 1 shows the system of complex analysis of business entity's creditworthiness. This scheme is based on the theory of economic analysis by scientists M.I. Bakanov and A.D. Sheremet [2]. The scheme reflects parts that are interconnected and ultimately lead to a single result - a comprehensive assessment of the borrower's creditworthiness.

1.Express analysis of the borrower's company, development and correction of analysis methods of creditworthiness assessment

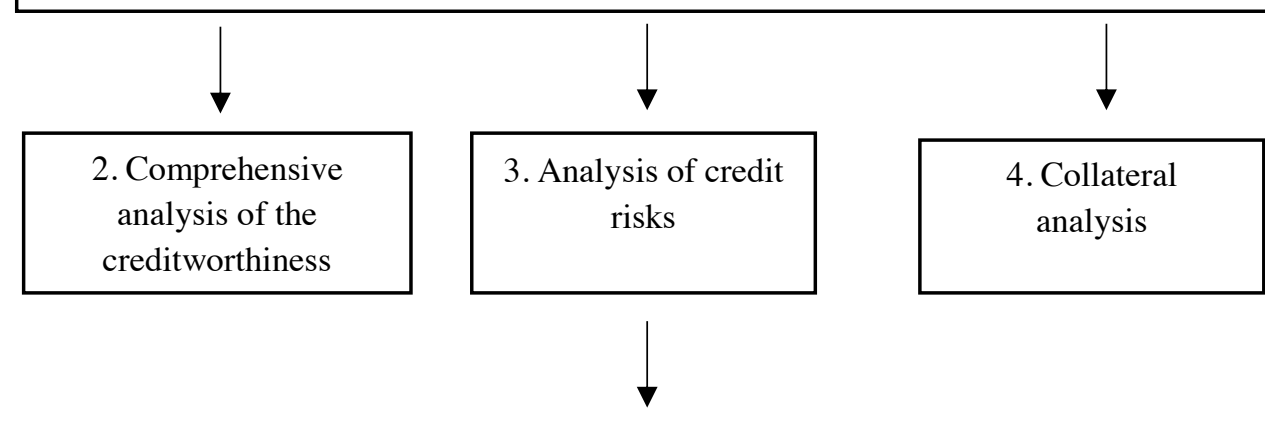

5.Results of analysis, formulation of conclusions and recommendations

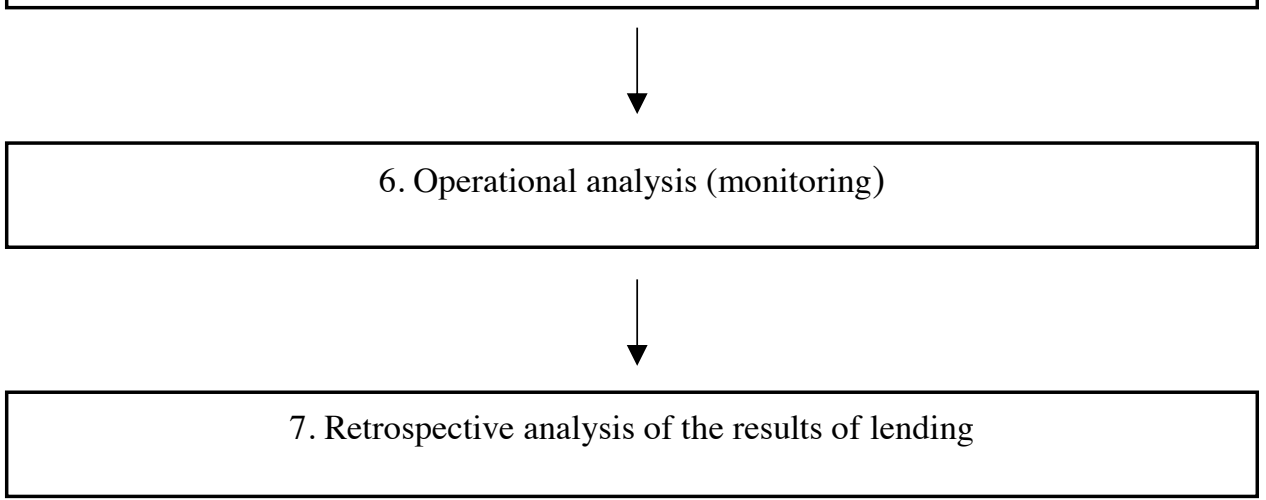

Fig. 1. System of comprehensive analysis of the borrower's creditworthiness Source: Own processing.

In this figure stages of conducting a comprehensive analysis of the creditworthiness are given, starting from an express analysis of the borrower, or initial analysis till a retrospective 
analysis of the results of lending or an analysis of previous credit transactions specifically with this borrower. In addition, the scheme reflects the important aspect that after a comprehensive assessment of the borrower's creditworthiness, the financial position of the borrower should be monitored.

Please refer to paragraph 1 of Figure 1.2. - Express analysis of the borrower organization. The concept of express analysis includes clarification of the purpose for issuing credit resources: the purpose of the loan, the regulatory and legal assessment of the documents of the company, an analysis of the company's belonging to a certain industry, a quick assessment of the provided loan security that is guarantors and collateral property. Also, additions to the analysis method can be included in the express analysis. Thus, analysts determine the list of tasks for analysis of creditworthiness at the stage of express analysis. It should be noted that the credit policy of each bank sets the main development directions for the bank, the formation of a loan portfolio. This means that the bank's credit policy provides information on the forms of the loan provided, on the rules for working with collateral on the loan and other important aspects [17].

At the stage of express analysis, loan resources requested by the borrower are checked for its correspondence with the priority directions for the formation of the bank's loan portfolio. Previous experience of the bank interaction specifically with the given borrower is also checked, the availability of all the required documents of the borrower is verified with clarification of its authenticity.

After the express analysis stage, analytical studies are carried out. Results of these studies are of great importance to bank analysts, since the conclusions obtained from a comprehensive analysis of the borrower's creditworthiness, assessments of credit risks and security on the loan are the information on which the decision to grant a loan to the borrower depends. Obviously, it is not possible to draw conclusions about the level of risk when granting a loan to a borrower if you use only an assessment of the creditworthiness of the business entity [21]. This thesis is especially relevant in modern market conditions, since at the moment there is a high probability of such credit risks that can not only destabilize the financial condition of the borrower, but also negatively affect the entire banking industry and the country's economy as a whole for example the financial crisis of 2008 serves as a vivid illustration of this.

The next aspect to be noted is the variability of the types of analysis. This means that operational and retrospective analyses are carried out in separate stages. In Figure 1, these are paragraphs 6 and 7 of the analysis. The special role of operational analysis, or monitoring, is determined by the fact that it is the basis of monitoring for the current financial situation of the borrower.[3] At the same time, the indicators obtained during monitoring are the initial data for the next stage of analysis that is retrospective analysis. The tasks of retrospective analysis include objective analysis's results of interaction between the borrower and the lender in terms of the loan agreement, discovery of negative and positive aspects of such interaction.

Currently, there are many different approaches to assessing creditworthiness. According to professors Bocharova I.V. and Endovitsky D.A., the classification of creditworthiness models proposed by professor Vishnyakov I.V. is successful [4]. This classification is shown in Figure 2. Each of the models presented in the classification will be described in detail below. The main thing to note is that approaches to assessing creditworthiness are divided into two types - classification and complex models [16]. 


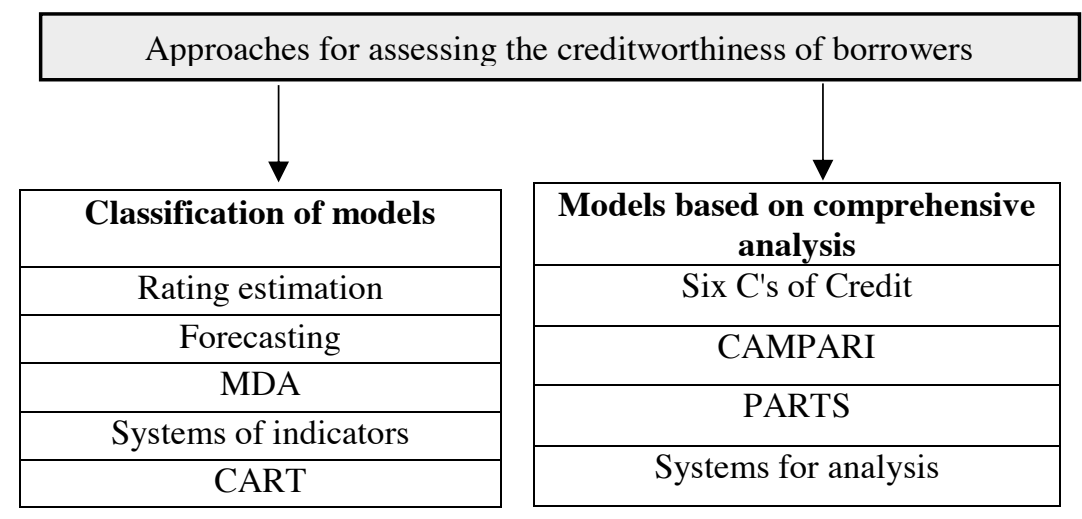

Fig. 2. Classification of models for assessing the creditworthiness of borrowers by Professor Vishnyakova I.V.

The rating estimation is an overall sum of the points. For each measure in the sum of the points, the points are calculated as follows: the value of the measure is multiplied by its weight, or significance factor. As a rule, when assessing creditworthiness based on a system of financial coefficients, groups of indicators are used, such as profitability ratios, liquidity ratios, financial sustainability ratios - among them, special attention is paid to the financial leverage ratio, turnover ratios and debt service quality ratios [18]. A slightly different system of indicators, which include ratios of profitability, liquidity, turnover, and fundraising that are used for defining various aspects of the creditworthiness of the company, was proposed by the American scientist Reed E. [1]. The set of these indicators allows you to determine the liquidity of current assets, analyze the complex financial situation of the borrower's company and its stability, evaluate the possibility of timely payments on borrowed money.

Also, on the basis of E. Reed's integrated system of indicators, it is possible to forecast the boundaries of lowering the volume of profit, in which the constant amount of loan payments is covered. With regard to banking practice, each commercial bank develops its own system of integrated indicators that are relevant to its credit policy. Rating models make it possible to assess the financial position of a borrower based on an indicator - a rating value, which is calculated in points assigned to each indicator value from a group of coefficients [15]. In accordance with the points scored for each borrower, the class of financial position is determined. Each commercial bank has a methodology that defines the most important financial ratios, their weights and scores, and a gradation of values that shows the quality of the borrower's financial position.

When issuing a bank loan, the in-house risk assessors (underwriters) carefully study the borrower's capabilities and determine his reliability. In his work, the underwriter uses the client databases available to him, as well as information received from the loan applicant. To make the information provided by a potential borrower most useful to the bank, underwriters use such a method as credit scoring.

The difference between credit scoring and a rating score is that in the rating score formula, its private score is used instead of the indicator value. For each indicator, several intervals of values are determined, each interval is assigned a certain number of points or a class is determined [2].

If the rating received by the borrower is lower than the value previously established by the bank's employees, then such a borrower will be denied a loan, and if it complies with the standards, the loan application will be satisfied. In this context, it should be noted that initially, the credit scoring model was focused on individual borrowers. Only later, when the model was worked out and its effectiveness was proven in consumer lending, the model was used to assess the creditworthiness of legal entities. 
For this work, 33 different enterprises were selected from different fields. All enterprises are different in scale of activity, so in order to bring the sample to a more homogeneous one, semilogarithmic regression was used, which is described below. First, a regression model was built that includes all available regressors in order to draw a conclusion about the most significant regressors based on the residual probability.

The use of regression analysis in the framework of a scoring model involves the construction of a significant regression, a model of the dependence of the score in the sum for financial risk and business risk from various risk factors [22].

In order to analyse the range of enterprises, you need to provide a description of the data with hypotheses.

As an example [23]:

Table 1. Description of the data with hypotheses

\begin{tabular}{|l|l|l|l||}
\hline \hline № & Variable name & \multicolumn{1}{|c|}{ Variable description } & \multicolumn{1}{c|}{ Hypothesis } \\
\hline 1 & Company_name & Company name, text variable & \\
\hline 2 & Scoring & $\begin{array}{l}\text { Scoring model scores (business } \\
\text { risk + financial risk) }\end{array}$ & Dependent variable \\
\hline 3 & Reserve & Reserve for possible losses, in\% & $\begin{array}{l}\text { The higher the reserve, the } \\
\text { lower the scoring points }\end{array}$ \\
\hline
\end{tabular}

Source: Own processing.

All characteristics should be given in detail in order to show why exactly they were taken for the regression analysis.

Further, from the set of characteristics of business risk and financial risk, the characteristics that best describe the sample should be taken, usually they describe indicators of business risk, indicators of financial risk, indicators of the structure of assets, the indicator of the structure of liabilities, indicators of the reserve and quality of the loan.

The selection of characteristics was made considering that:

1) most enterprises have this characteristic;

2) it is more important for the Bank;

3) according to opinion about the influence of this characteristic on the creditworthiness of the enterprise.

The next step is to build a regression on the characteristics of the creditworthiness risk, which can reflect both the real and the expected impact on the creditworthiness of the enterprise. 
Table 2. Semi-log regression.

\begin{tabular}{|c|c|c|c|c|}
\hline \multicolumn{5}{|l|}{ Dependent variable: scoring } \\
\hline \multicolumn{5}{|l|}{ Method: least squares } \\
\hline \multicolumn{5}{|c|}{ Sample: 133 IF SCORING >=20 AND RESERVE $<0.4$} \\
\hline \multicolumn{5}{|l|}{ Included observations: 27} \\
\hline Variable & Coefficient & Std. Error & t-Statistic & Prob. \\
\hline Market_share & 4.408732 & 6.127710 & 5.719475 & 0.0302 \\
\hline Supplier_dependence & 4.037292 & 4.244107 & 6.951270 & 0.0228 \\
\hline Log(current_liquidity) & 7.994769 & 7.023251 & 3.138329 & 0.0184 \\
\hline Log(sales_profitability) & 0.540752 & 1.742451 & 3.310340 & 0.0295 \\
\hline Log(equity_to_debt_relation) & 3.479767 & 1.588918 & 2.190022 & 0.0405 \\
\hline Log(shortterm_borrowings) & -0.214523 & 1.038432 & 4.206584 & 0.0384 \\
\hline $\mathrm{C}$ & 62.45646 & 9.793678 & 6.377222 & 0.0000 \\
\hline R-squared & 0.864072 & \multicolumn{2}{|c|}{ Mean dependent var } & 49.77222 \\
\hline Adjusted R-squared & 0.783293 & \multicolumn{2}{|c|}{ S.D. dependent var } & 10.96788 \\
\hline S.E. of regression & 10.72783 & \multicolumn{2}{|c|}{ Akaike info criterion } & 0.801974 \\
\hline Sum squared resid & 2301.727 & \multicolumn{2}{|c|}{ Schwarz criterion } & 0.137932 \\
\hline Log likelihood & -98.32665 & \multicolumn{2}{|c|}{ Hannan-Quinn criter. } & 0.901872 \\
\hline F-statistic & 34.19609 & \multicolumn{2}{|c|}{ Durbin-Watson stat } & 1.933245 \\
\hline Prob(F-statistic) & 0.348360 & & & \\
\hline
\end{tabular}

Source: Own processing.

This model has a high explanation - the coefficient of determination is 0.86 . The $\mathrm{F}$ statistic is also high at 34 , which suggests that the model is significant overall. The coefficients are significant individually, since the t-statistics are high, and the residual probabilities are close to unity. Thus, the resulting model of the Scoring dependency was obtained - the sum of scoring points for financial risk and business risk, and individual indicators of financial and business risk.

\section{Results}

So, the following tasks were set and completed:

1. a basic model of the influence of 6 regressors on scoring was built.

2. it was analysed based on various tests. 
3. additional models are built.

\title{
Estimation Equation:
}

\author{
Scoring $=$ \\ $\mathrm{c}(3) * \log$ (current_liquidity) \\ $\mathrm{c}(1)^{*}$ market_share $\quad+$ \\ $+\quad \mathrm{c}(2)^{*}$ supplier_dependence \\ $+$ \\ $+\mathrm{c}(4) * \log ($ sales_profitability) $+\mathrm{c}(5) * \log ($ equity_to_debt_relation) $+\mathrm{c}(6) * \log ($ shortterm_borrowin \\ gs) $+\mathrm{c}(7)$.
}

During regression analysis, the following conclusions were obtained: firstly, the linear model is not suitable for reflecting the dependence of scoring points on risk indicators. In this case, the reason for this is the high heterogeneity of indicators, high coefficients of variation of explanatory variables.

Thus, a model of the dependence of scoring points on the most important indicators of financial risk and business risk has been built. It should be noted that the model results were obtained based on calculations for 33 enterprises. The model shows changes in scoring points with an increase or decrease in the most important indicators of risk. Using the model, you can find how much the sum of scoring points will increase or decrease when the most important indicators decrease or increase. A possible drawback of the model is the small number of observations, based on which the calculated indicators were obtained.

The essence of the scoring method consists in questioning the client, the result of which affects the bank's decision to issue a loan. Each question in such a scoring card (questionnaire) is assigned a certain number of positive or negative points. In many processing models, the scores do not take negative values and carry a strictly regulated quantitative and evaluative component [5]. The point total gives a general understanding of the client's creditworthiness, and an in-depth analysis of the combination of factors gives the optimal solution that excludes the subjective perception of the underwriter [6].

Bank risk assessors in their work use mathematical algorithms for questioning scoring models. The scoring algorithm is developed in accordance with the general credit policy of the bank and loaded into the bank's computer system connected to various databases. Scoring models determine the quantity and quality of questions, their scoring and positional placement. In young banks, underwriters are armed with only two or three models of scoring questionnaires. The lending policy of experienced banks forces underwriters to keep a variety of scoring models close at hand, often complicated by querying questionnaires. For example, a positive answer to a question about a criminal record does not give a complete picture of the client's reliability. An extinguished or conditional conviction for fraud carries a significant number of negative points, while a conviction for a petty domestic crime may not have any point weight at all within the scoring model.

The early world experience of bank lending included the mandatory principle of letters of credit and recommendations for new borrowers [8]. The authoritative guarantor was personally responsible with business reputation for the credit good faith of his protégé. With the advent of affordable lending in the United States at the beginning of the 20th century, the banking system was swept by a wave of fraud and loans from clients with overvalued financial capabilities. If before that, US banks dealt with a narrow circle of the financial and industrial establishment, then the new system of "loans for everyone" provoked a massive influx of borrowers. The Great Depression (1929-1939) exposed the depth of the problem. There was a need for a new system for quick and high-quality assessment of the client's potential. In 1941, researcher D. Durand for the first time created an algorithm for recognizing the reliability of customers based on a point calculation. And in 1956, mathematician Earl Isik, in collaboration with engineer Bill Fire, developed the first full-fledged scoring model for determining the creditworthiness of citizens. Simplified scoring models of questionnaires in those years easily identified unreliable loan applicants. This was facilitated by the general illiteracy of citizens, including those who deliberately took out a loan in order to not return it. When the fraudulent 
environment shifted from audacious adventurism to cunning schemes, credit policy was forced to complicate all its assessment tools. Now, competent scoring models not only analyze the information provided by the client, but also immediately double-check it. Sustainable banks always could check customer data and determine his sincerity when questioning [7].

\section{Discussion}

Modern algorithms of scoring systems are capable of automatically assessing a client's creditworthiness. The type of such screening models was called Application-scoring. Fraudscoring algorithms are responsible for identifying suspicious factors indicating an overestimation of personal data. Also, the banking system monitors changes in the client's financial capabilities (new loans, collection by court, irrecoverable loss of property, market reduction in the price of collateral assets, etc.). Changes in the score of the client allows you to predict the risks of non-repayment of the loan taken by him. This turns on the algorithm of the Collection-scoring models (English - a collection of methods for a set of points), which, based on all current parameters and data about the client, give the optimal strategy of actions [8].

These unique tools help the bank to respond flexibly to potential lost profits.

Thus, the problems that the credit scoring model can solve are as follows:

1. subjectivity - often decisions made by loan officers are based only on intuition and personal experience;

2. inflexibility and instability - the quality of the assessment is a random variable that cannot be improved or worsened, and depends on the emotional state and preferences of the expert;

3. lack of a system of training, knowledge transfer and advanced training - before becoming a highly qualified specialist, it is necessary to accumulate a certain level of knowledge based on the acquisition of sufficient experience in this area;

4. limitation of the number of considered applications, which is due to limited physical resources of a person, as a result of this - lost profit from a small number of applications under consideration.

You can try to solve these shortcomings using a scoring model, since its advantages are simplicity (since it is enough to calculate financial ratios and, taking into account the coefficients of their significance, to determine the class of the borrower), the ability to calculate optimal values by particular indicators, the ability to rank organizations by results, an integrated approach to assessing creditworthiness (since indicators are used that reflect various aspects of the organization's activities) [10].

For the first time, Russian researchers used logistic regression models to compile scoring maps [11]. Dependent and independent variables were included in the processing algorithm of the scoring program, and methods for their analysis and correction were determined. This made it possible to significantly improve the predictability of the borrower's creditworthiness based on his verified social and demographic data. Belarusian scientists are not lagging behind their Russian colleagues who have applied statistical analysis of multivariate data of complex structure such as data mining to the scoring model [12]. And although Western scientists continue to hold the palm in the development of models for assessing banking risks, new geopolitical challenges have given extraordinary dynamism to domestic scientific thought in relation to the banking sector of the Russian Federation.

\section{Conclusion}

The scoring model is one example of the successful application of statistical and mathematical methods. However, the scoring model has not become widespread in Russia. 
According to G. Andreeva, the widespread use of scoring is hindered not so much by objective as by subjective reasons, of which the main reason is the mistrustful attitude of bank managers towards mathematical and statistical methods [13]. If we talk about domestic banks, then the use of scoring models in banks is combined with expert judgment.

In banks, for each large enterprise - the borrower, a responsible loan officer is appointed who oversees the financial analysis of this borrower. Due to the low development of scoring models, it will be interesting to consider this topic on the example of a specific bank.

Most experts agree that scoring models were originally a temporary solution for assessing risks. However, the indisputable achievement of scoring modeling has become a quick filtering from borrowers who overestimate their financial capabilities. Namely, this category caused the greatest damage to the banking sector at the time of the emergence of the system of affordable lending [19].

The emergence of new technologies and the merging of the banking sector with state structures predetermines new forms of accounting for the reliability of citizens. In developed countries, banking customer questionnaires, instead of comprehensive testing, involve answering just a few questions. Such decorative formalization is due to the fact that in a highly informative world it is impossible to keep personal data secret [14]. In a modern digitalized state, all information about a loan applicant can be extracted without the participation of the applicant himself. And the data obtained in this way are processed by computer programs with more efficient algorithms than the scoring model with a rough scoring method.

\section{References}

1. M. Krejnina, Financial management. Moscow: Business and service (2002)

2. Klyachkin, V.N., Shunina, Yu. S., System for Borrowers' Creditworthiness Assessment and Repayment of Loans Forecasting, Vestnik komp'yuternykh i informatsionnykh tekhnologii, 11, p. 45-51 (2015), Available at: http://ezpro.fa.ru:2070/full_record.do?product=RSCI\&search_mode=GeneralSearch\&qid= 1\&SID=E1 pr5h7xBiIjA2egM5z\&page=1\&doc=10\&cacheurlFromRightClick=no

3. Francisco Louzada, Paulo H. Ferreira-Silva, Carlos A.R. Deniz (2012) On the impact of disproportional samples in credit scoring models: An application to a Brazilian bank data // Expert Systems with Applications, 39(9,3). Available at: http://www.sciencedirect.com/science/article/pii/S0957417412001522

4. M. Bakanov, A.Sheremet, Theory of economic analysis. 5th ed. Moscow: Finances and statistics (2002)

5. E. Solozhencev, N. Stepanova, V. Karasev. Transparency of credit risks and ratings evaluation methods. St. Petersburg: St. Petersburg University Publishing House (2006)

6. I.Vishnyakov. Methods and models of assessing the creditworthiness of borrowers. St. Petersburg: SPbSUEE (1998)

7. V.Starshinov, System realization of credit scoring as a professional system to assess clients' solvency. Information technologies in science, management, social sphere and medicine. -V Intenational science conference (2018)

8. Vernikov, A. Mamonov, M., Modelling technical efficiency of firms under one-step and two-step approaches (the case of commercial banks), Applied Econometrics, 1, p. 67-90 (2018), Available at: http://ezpro.fa.ru:2070/full_record.do?product=RSCI\&search_mode=GeneralSearch\&qid= 25\&SID=E1pr5h7xBiIjA2egM5z\&page $=1 \&$ doc $=8 \&$ cacheurlFromRightClick=no 
9. O. Vorobyeva, Scoring model of creditworthiness evaluation. Moscow: Aktion Management and Finance (2020)

10. I. Vorobyeva, Improving the Methodology of Credit Scoring of Borrowers in Car Lending, Den'gi i kredit, 8, p. 34-39 (2013), Available at: http://ezpro.fa.ru:2070/full_record.do?product=RSCI\&search_mode=GeneralSearch\&qid= $25 \&$ SID $=$ E1pr5h7xBiIjA2egM5z\&page $=2 \&$ doc $=16$

11. Panyagometh, K., Credit scoring by incorporating dynamic networked information, Economics \& sociology, 1, p. 262-269 (2019), Available at: http://ezpro.fa.ru:2070/InterService.do?fromPID=RSCI\&product=UA\&toPID=UA\&return Link=http $\% 3 \mathrm{a} \% 2 \mathrm{f} \% 2$ fapps.webofknowledge.com\%2ffull_record.do\%3fhighlighted_tab $\% 3$ dRSCI\%26last_prod\%3dRSCI\%26excludeEventConfig\%3dExcludeIfFromFullRecPage

12. V. Selyukov, Optimization of Credit Risk Management in Banking Scoring Systems, Herald of the Bauman Moscow State Technical University. Series: Natural sciences, 1, p. 106-118 (2012), Available at: http://ezpro.fa.ru:2070/full_record.do?product=RSCI\&search_mode=GeneralSearch\&qid= $31 \&$ SID $=$ E1pr5h7xBiIjA2egM5z\&page $=4 \&$ doc $=36$

13. A. Masyutin, Credit scoring based on social network data, National Research University Higher School of Economics, Business Informatics (2015), 3, p. 15-23, Available at: http://ezpro.fa.ru:2070/full_record.do?product=RSCI\&search_mode=GeneralSearch\&qid= 1\&SID=E1 pr5h7xBiIjA2egM5z\&page $=1 \&$ doc $=9 \&$ cacheurlFromRightClick=no

14. Y. Zhosan, Methods of selective data combination in terms of credit scoring limitations. Moscow: Moscow State University Publishing House (2017)

15. A. Sorokin, Creation of scoring schemes with the use of logisctic regression models. Vestnik evrazijskoj nauki, 2 (21) (2014)

16. N.V. Grin', Methodological aspects of scoring models. Available at: https://docplayer.ru/35162944-Metodologicheskie-aspekty-postroeniya-skoringovyhmodeley-n-v-grin-grodnenskiy-gosudarstvennyy-universitet-imeni-yanki-kupaly.html (2012)

17. G. Andreeva, Scoring as a method of credit risk evaluation. Bank technologies, № 6 (2000)

18. Li Yibei, Wang Ximei, Credit scoring by incorporating dynamic networked information, European journal of operational research, 3, p. 1103-1112 (2020), Available at: http://ezpro.fa.ru:2070/InterService.do?fromPID=RSCI\&product=UA\&toPID=UA\&return Link=http $\% 3 \mathrm{a} \% 2 \mathrm{f} \% 2$ fapps.webofknowledge.com

19. O. Zakharova, Development of a model of an information system for managing a lending process and an algorithm for cross-selling to bank borrowers, Software systems and computational methods, 1, p. 51-58 (2019), Available at: http://ezpro.fa.ru:2070/full_record.do?product=RSCI\&search_mode=GeneralSearch\&qid= 31\&SID=E1pr5h7xBiIjA2egM5z\&page $=1 \&$ doc $=4 \&$ cacheurlFromRightClick=no

20. V. Salin, Statistical analysis of a banking system of Russia, Vestnik Finansovogo universiteta, $\quad 6, \quad$ p. 107-115 (2015), Available at: http://ezpro.fa.ru:2070/full_record.do?product=RSCI\&search_mode=GeneralSearch\&qid= 31\&SID=E1pr5h7xBiIjA2egM5z\&page=2\&doc=13\&cacheurlFromRightClick=no

21. V. Aleshin, Credit scoring is a tool to improve the quality of bank risk management in contemporary conditions, Terra Economicus, 10 (2-3), p. 27-30 (2012), Available at: 
http://ezpro.fa.ru:2070/full_record.do?product=RSCI\&search_mode=GeneralSearch\&qid= $31 \& \mathrm{SID}=\mathrm{E} 1 \mathrm{pr} 5 \mathrm{~h} 7 \mathrm{xBiIjA2egM} \mathrm{z} \&$ page $=3 \& \mathrm{doc}=28 \&$ cacheurlFromRightClick $=$ no

22. Christian Bluhm, Ludger Overbeck, Christoph Wagner. «Introduction to Credit Risk Modeling», second edition, USA: Chapman and Hall/ CRC Financial Mathematics Series, 2010,383 p. 